\title{
ROBOT ORIENTED DESIGN OF REUSABLE PARTITION WALLS WITH INTEGRATED BUILDING AUTOMATION CAPABILITIES
}

\author{
Thomas Bock ${ }^{1}$, Helga Meden ${ }^{1}$, Jana Timmermans ${ }^{1}$, Ron Unser ${ }^{1}$ \\ ${ }^{1}$ Chair for Realization and Informatics of Construction, \\ Faculty of Architecture, Technische Universität München, Arcisstr. 21, 80333 Munich, \\ Germany \\ thomas.bock@bri.ar.tum.de
}

\begin{abstract}
In the long run reusable partitions walls have lower costs and are more economical and especially more variable compared to convenient post-and-beam-structures. Because room requirements - mainly in office and administration building - change faster and faster, an extensive potential on future markets for these technologies exists.
\end{abstract}

Keywords: Flexibility, Economic Efficiency, Non-supporting removable wall-unity, Media- and electric wiring, Put-and-slide-technology, Relocate systems, Cost, Different Elements, Adapted assembly robot system.

\section{INTRODUCTION}

A higher and higher flexibility of the floor plan is expected in office- and commercial building as in house building. The change of users or function often results in the wish redesigning the existing spatial pattern. A basic floor plan flexibility often is possible and practiced by dividing the loadbearing building surface from non-structural separation walls and ceilings. A well known system of this type of walls is a wooden or metal post-and-beam-structure with mineral fibre filling and plasterboard panelling. By using this building system it is difficult to realize variations of different room structures and subdivisions by self building. In fact they are cheap to produce and to install but in the end they are much fuss in redesigning, few flexible and actually not reusable. In addition there are already reusable, demountable partition systems available. However they usually are to expensive and to much fuss to construct.

Together with partners from industry, the Department for Building Realization at the University of Technology, Munich, Prof. Dr. Bock, is involved in the development of flexible partitions. The following qualities were defined as important objectives for a viable system:

- The elements should be demountable - without causing damage to the existing structure - and capable of reuse.

- They should have a finished surface on both sides and provide a complete lightweight construction system.
- A maximum of two persons should be able to handle and assemble the elements.

- The elements should provide the boundary conditions to be handled and assembled by an automated device, which will be developed in a following project.

- The price should lie between that for standard plasterboard partitions with metal studs and other existing partition systems.

- The elements should have a simple form of construction that would enable a joiner to carry out repairs.

- It should be possible to incorporate additional functions and fixtures, such as monitors, lamps, shelving, ventilation, etc.

\section{ECONOMIC VIABILITY OF EXISTING SYSTEMS}

The economic viability of a prefabricated system in comparison with conventional plasterboard stud partitions - is not determined by the investment costs alone. The costs incurred in the course of its life and the costs it saves compared with other systems also have to be taken into account. The viability of prefabricated systems increases with each reuse.

- With careful planning, the costs of creating the abutments with adjoining sections of a building will be roughly the same for both prefabricated and conventional plasterboard types.

- The surface quality of plasterboard partitions is lower than that of industrially prefabricated systems. - Finally, savings that offset additional investment will become apparent when prefabricated partitions 
are dismantled and reused in a different location. Whereas the cost of relocating a prefabricated partition is about 30 per cent of the investment costs, the cost of removing a plasterboard stud partition and re-erecting it elsewhere amounts to about 150 per cent of the investment costs. The amortization of a wall construction system will, therefore, depend on the number of times it is dismantled and re-erected.

- Other factors to be considered are the economic and environmental costs of disposal. Systems that can be reused have obvious advantages in this respect: they conserve raw materials, reduce building waste and help to avoid disposal charges.
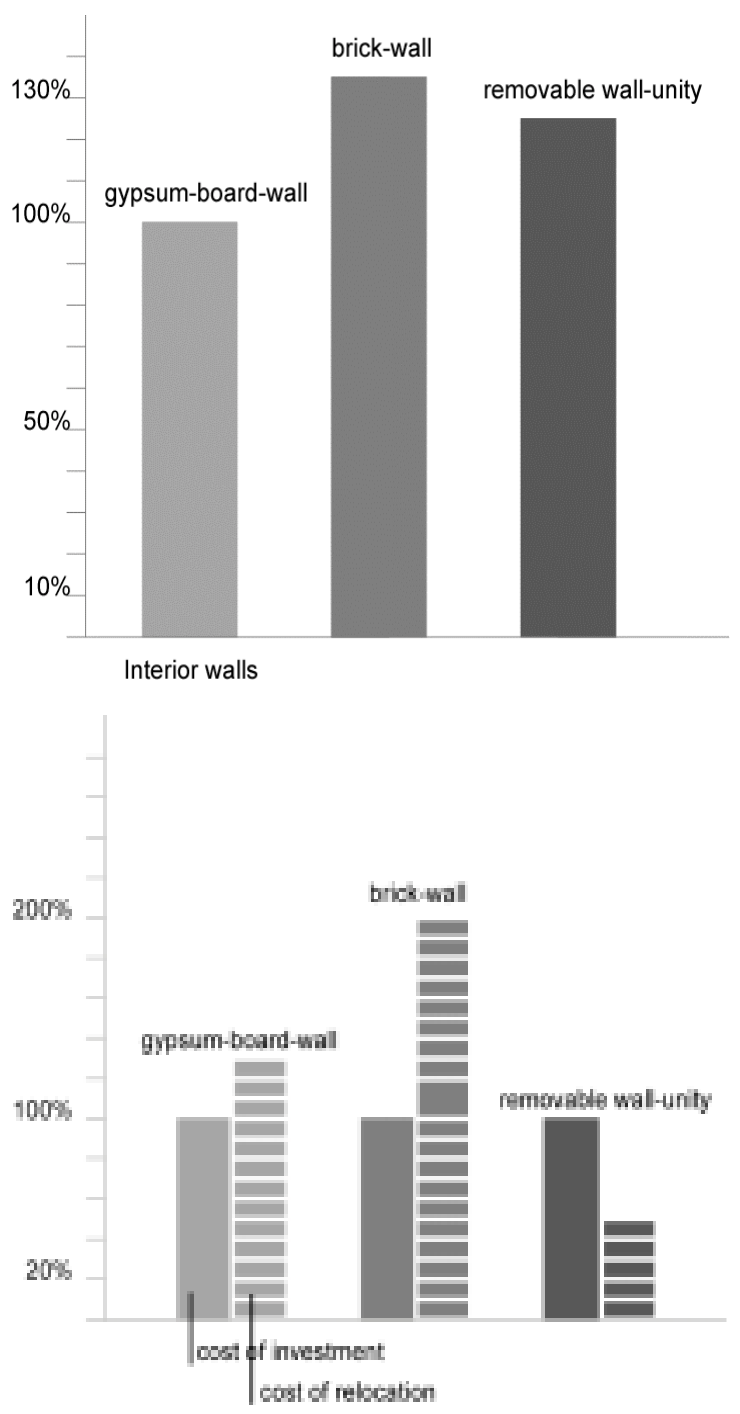

Fig. 1 Interior walls: cost of investment and relocation

\section{ELEMENTS}

Assuming a sensible separation of the structure and finishings, the geometry of the wall elements will be based on the room height. Various panel widths are possible. Our system is based on a $20 \mathrm{~cm}$ module (with unit widths ranging from 20 to 120 $\mathrm{cm}$ in $20 \mathrm{~cm}$ stages). Although widths above 120 $\mathrm{cm}$ are possible, but they are not recommended in view of the weight of elements fulfilling both: human and robots request on maximum load.

In addition to the wall elements, L"- and T-sections are necessary to form angles and intersections. In keeping with the grid dimensions, the legs of these members are $20 \mathrm{~cm}$ long. Other system elements include door and clerestory units and end sections.
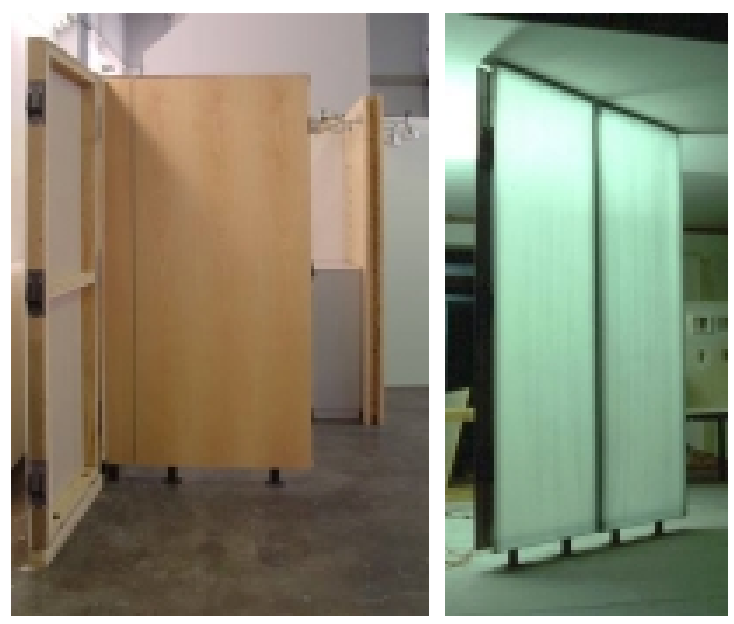

Fig. 2 Timber-framed partition element, all-glass element

\section{CONSTRUCTION}

The supporting structure for the individual elements comprises a peripheral frame $70 \mathrm{~mm}$ deep. The frame can consist of glued timber or special welded metal sections, cut to mitre at the corners. The rigidity of the frame has to allow dynamic handling with future interior robots. In addition it should provide space for gripping.

Suitable materials for the surface finish include wood sheeting, gypsum fibreboard, glass, etc., which also provide stiffening. A $30 \mathrm{~mm}$ soft-fibre layer around the frame improves acoustic insulation in the area of abutments and joints. Abutments with existing structural walls are created with a special section with recessed shadow joints. The individual wall elements are connected to each other by dovetail interlocking members with a self-centring geometry and with integrated plugs and sockets to allow the passage of various media from one element to another.

By the restriction on few standardized construction components an automated manufacturing can be realized easily. With only one pair of fast 
connectors, two kinds of frame cross sections (wood and stainless steel) and a standardized cable harness all kinds of elements can be manufactured on only one assembly desk. The surface materials can be varied at will, but at the same time handled with the same vacuum gripper.

\section{CONNECTORS}

The plastic connectors used in the system under development are produced under licence by the Fischerwerke company. They allow a tight mechanical connection of the wall elements and a simultaneous link-up of all media within the unit, including electricity. Up to three connectors per wall element are possible.
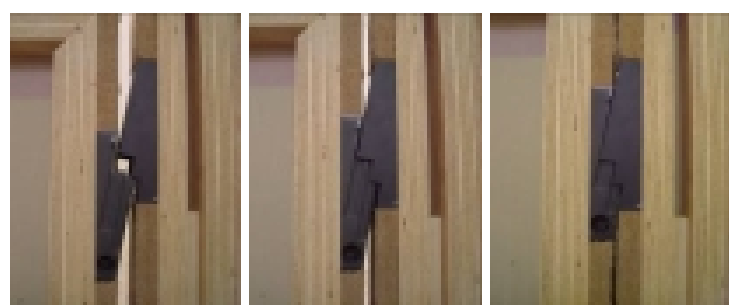

Fig. 3 System connector in timber stud wall

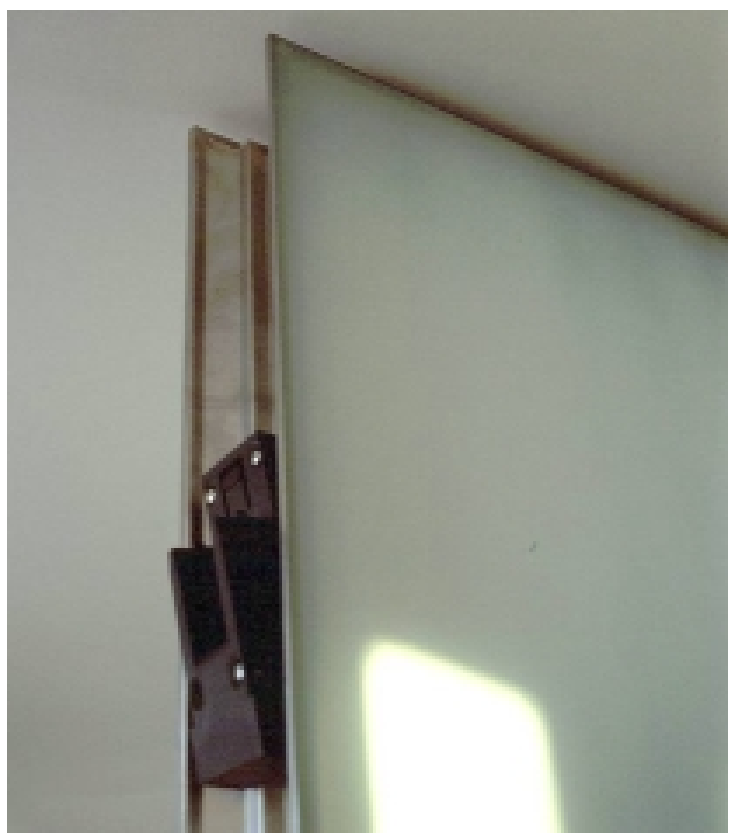

Fig. 4 System connector and soffit abutment
Every wall element stands on two $15 \mathrm{~cm}$ threaded feet fixed in the frame. The feet should be in a retracted position when the element is placed in position. By adjusting the height of the feet, the units can be precisely levelled and raised until they are pressed tightly against the soffit. An adjustment height of up to $11 \mathrm{~cm}$ is possible. When one element is fixed in position, the next one can be installed alongside it.
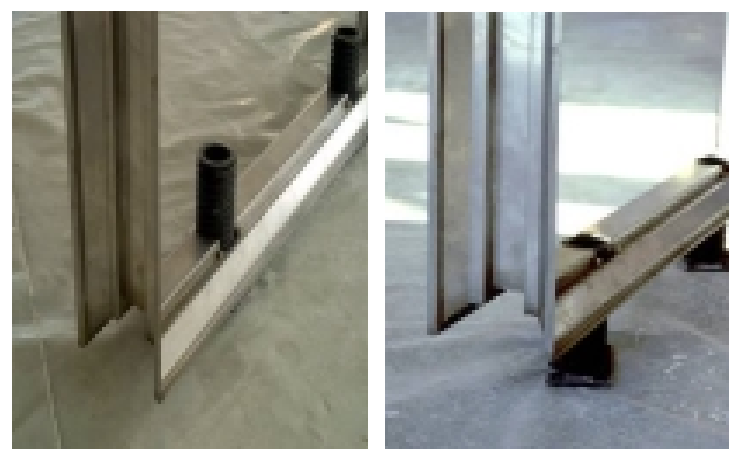

Fig. 5 Floor connection with metal section and adjustable threaded feet

\section{ASSEMBLY}

Not more than two persons are required to assemble the wall elements. Where a partition abuts a structural wall, the assembly should begin at that end. In the case of a freestanding configuration, the assembly can begin at either end. When the second element is initially placed in position, the two halves of the system connector will be slightly offset to each other. They interlock when the new element is adjusted in height. The same principle applies to the assembly of corner connections and intersections. The erection sequence is concluded by inserting a closing piece in the space at the end. The void between the base of the elements and the floor remains accessible for adjustments and additional installations. It is filled with a soundinsulating mat and closed with a compression strip that forms a flush skirting. To dismantle the wall, the assembly process is simply reversed. The assembly/dismantling time for the present system, is about 15 minutes per element $(80 \times 240 \mathrm{~cm}$, or roughly two square metre).

By using an adapted assembly robot system this procedure could be overtaken and should halve clock cycle.

The assembly process is very simple and is limited to movements, which can be taken over easily by autonomous robots: Supplying robots can take over the transport of afore calculated element packages to the erection place, while assembly robots determine the assembly position accurate to a millimetre on the basis of Tracking-Systems like

\section{THREADED FEET}


GPS. By the self centring of the fast connectors the position of the next construction component is given. Assembly work hereby also consists in the adjustment of the elements by the vacuum gripper and following in the raising of the feet for the spanning of the wall between flooring and ceiling.

\section{ELECTRIC PREINSTALLATION, LED}

Special processing of the frame sections allows a preinstallation of electric cables within the elements. Where a transparent surface is desired, the cables can be concealed in the frame. Any switches or socket outlets should ideally be installed during the manufacture of the elements, although they can also be fitted subsequently. Additional cables (e.g. for telephones, computer networks, etc., where connections are less desirable) can be installed in the space at the foot of the elements.

Due to the possibility of reusing the elements, it is worth integrating high grade building automation components. Using bus connection, every type of circuit according to every floor plan variation can be set. Custom-made elements with integrated electronic devices or computing can be fabricated as well.

All-glass models are also possible with sandblasted or coated surfaces and with invisible frames. The glass is adhesive fixed to the frame to create a rigid composite element.

Three-colour LEDs integrated in the bottom of the cavity between the panes permit the elements to be illuminated.

In autumn 2003, a complete office floor divided by these partition elements was installed. By combining red, green and blue devices every colour of light can be adjusted. Thereby the elements can indicate directions or also be integrated into a consistent environment.

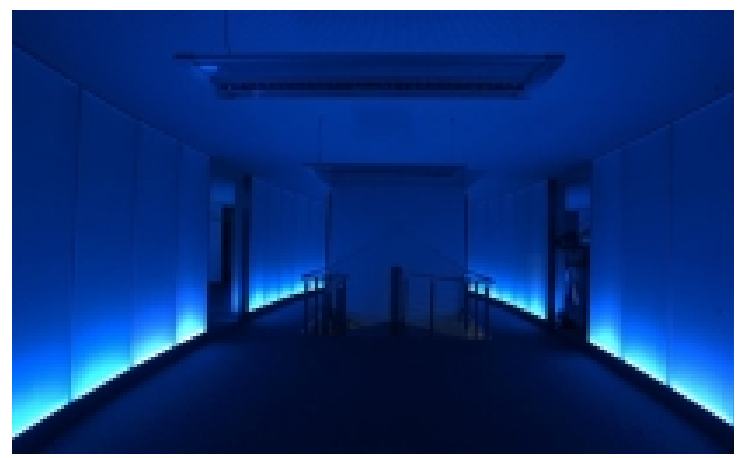

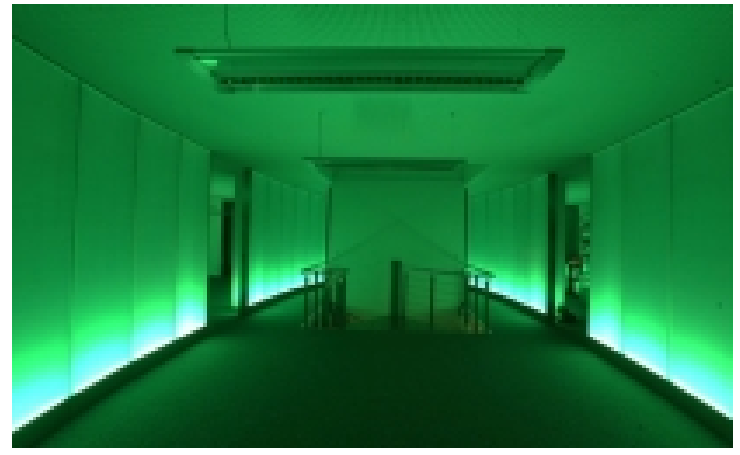

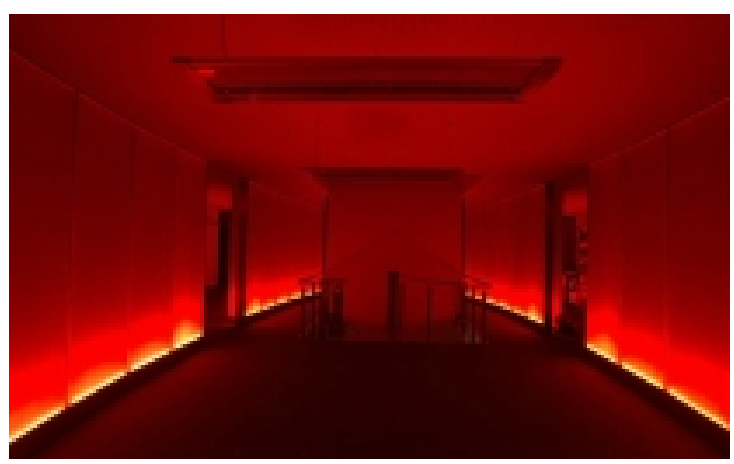

Fig. 6 Partition elements with integrated threecolour LEDs in an office floor

\section{Acknowledgments}

The author holds the chair of the Department for Building Realization of the University of Technology, Munich.

The article was written in collaboration with Helga Meden, Jana Timmermans and Ron Unser.

The project is supported in equal parts by the Bavarian Ministry of Trade and Commerce and the industrial partners Baierl \& Demmelhuber, Innenausbau $\mathrm{GmbH}$, Töging and Rigips $\mathrm{GmbH}$, Düsseldorf

\section{REFERENCES}

Studiengemeinschaft Fertigbau:

Trennwandsysteme, 1987

T. Bock, University of Tokyo:

Robot Oriented Design, Shokokusha Publ.Co. Tokyo, May, 1988

Tichelmann / Pfau:

Entwicklungswandel Wohnungsbau, Vieweg, Wiesbaden, 2000

Diverse Herstellerunterlagen:

Lindner, Knauf, Item, Dorma, Häfele, Strähle, Hettich, u.a. 